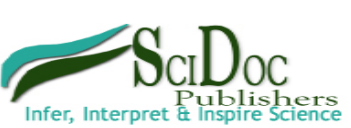

\author{
International Journal of Ophthalmology \& Eye Science (IJOES) \\ ISSN 2332-290X
}

\title{
Daylight For Healthy Indoor Environment And Energy Benefits
}

Ullah I

Editorial

Department of Information and Communication Engineering, Myongij University, San 38-2 Nam-dong, Yongin, South Korea

\section{*Corresponding Author:}

Irfan Ullah,

Department of Information and Communication Engineering,

Myongji University, San 38-2 Nam-dong,

Yongin, South Korea

E-mail: irfan@mju.ac.kr/irfan752@live.com

Received: January 18, 2014

Published: January 20, 2014

Citation: Ullah I. (2014). Daylight for Healthy Indoor Environment and Energy Benefits, Int J Ophthalmol Eye Res, 02(2e), 01-02. doi: http://dx.doi.org/10.19070/2332-290X-140003e

Copyright: Ullah $\mathbf{I}^{\odot} 2014$ This is an open-access article distributed under the terms of the Creative Commons Attribution License, which permits unrestricted use, distribution and reproduction in any medium, provided the original author and source are credited.

Recently, many researchers have been concerned to the interaction between environment and energy. Daylighting serves for both to improve indoor environment as well as to save energy utilization. It is clear throughout history that daylight has been an important element to affect health and lighting quality in the architectural designing. Different methods have been developed to bring daylight inside the building. Most of the methods have not been adopted because of their low efficiency and installation problems. What is the possible solution and current need to provide daylight in the buildings?

Besides energy saving, daylight has positive influence, which improves the quality of life, on the human body (e.g., feelings and emotions). Daylight research has shown that it can be used to reduce the impact of illnesses (e.g., seasonal affective disorder) and improve patient recovery rapidly [1]. As daylight includes visible and non-visible light, the eyes and skin absorb non-visible wavelengths that are needed to synthesize vitamin D3. People spend most of their time under artificial light in buildings. As a result, $15 \%$ of office workers complain of eye strain, and 78 million have calcium deficiency due to insufficient vitamin $\mathrm{D}[2]$. Low levels of vitamin $\mathrm{D}$ have been shown to increase the risk of strokes and heart attacks by $60 \%[1]$. In general, most of the people prefer to work in a daylighted interior space rather than a non-daylighted interior space. An integrated daylighting design must be incorporated into a building design to produce comfortable indoor environments for healthy lifestyle.

Daylighting has a significant role in the field of renewable energy to reduce energy consumption. It is estimated that buildings are the main source of $\mathrm{CO}_{2}$ emissions where $46 \%, 71 \%$, and $50 \%$ of total energy is consumed in buildings of South Korea, USA, and Hong Kong, respectively [3,4]. Electric lighting energy utilization in buildings is $40-50 \%$ of the total energy cost [5]. One of the principles of sustainable buildings is to utilize daylight at all day for lighting. Buildings that include daylight with lighting control system, which maintains light level in the interior space, are estimated to reduce electric lighting energy consumption by $50-80 \%$ [6].

Several concepts regarding daylighting schemes have been demonstrated with opening places [7], windows [8], skylights [9], micro lenses [10], redirecting mirrors [11], light pipes [12], light guides [13], and optical fibers [14,15]. Windows are most common daylight transmitting device in the interior space, but research is in progress to redirect the light for achieving uniform indoor illumination[10]. Skylights are incorporated into the roof of the building; however, these are not suitable for multi-floor buildings. Light pipes are not preferred because they have low transmitting efficiency. Most of the daylighting strategies give non-uniform illumination, which produce visual discomfort, in the interior space. Only optical fibers are capable of fulfilling the requirements for buildings. Current need is to design daylighting methods for newly constructed multi-floor buildings. Researchers have introduced different methods to deliver uniform daylight in multi-floor buildings using optical fibers [16], but most of the methods are in the early stages of development and implementation of the system.

There is no doubt that daylighting provides high quality illumination and health benifits. Using daylight, office worker's performance and patient recovery can be increased. To provide daylight in the interior space, more consideration should be given to make the light collecting system efficient in terms of light concentration and manufacturing process. An appropriate daylighting strategy will lead us to a solution to the energy problem and healthy indoor environment.

\section{References}

[1]. H. Braun, Photobiology: The Biological Impact of Sunlight on Health \& Infection Control, Phoenix Project Foundation, 2008.

[2]. Dr. A. Dunne, Some Effects of the Quality of Light on Health, J Orthomol Med 4 (1989) 229-232.

[3]. Annual Energy Outlook 2007: With Projections to 2030, U.S. Energy Information Administration, 2007.

[4]. T.Y Chen, J Burnett, and C.K Chau, Analysis of embodied energy use in the residential building of Hong Kong, Energy 26 (2001) 323-340.

[5]. A. Ossa, D. A. Gottfried, T. Walsh, and L. N. Simon, Sustainable Building Technical Manual: Green Building, Design, Construction and Operations, US: Public Technology Inc., 1996.

[6]. Green Building Rating Systems-Draft Recommendations for a U.S. Rating System. U.S. Green Building Council, Bethesda, Md., August 13, 1995.

[7]. M. Andersen, S. J. Gochenour, and S. W. Lockley, Modelling 'non-visual' effects of daylighting in a residential environment, Building and Environment 70 (2013) 138-149.

[8]. S. Yoo, J. Kim, C.Y. Jang, and H. Jeong, A sensor-less LED dimming system based on daylight harvesting with BIPV systems, Opt. Express 22 (2014) 
A132-A143

[9]. M. Paroncini, B. Calcagni, and F. Corvaro, Monitoring of a light-pipe system, Solar Energy 81 (2007) 1180-1186.

[10]. S. Klammt, A. Neyer, and H. F.O. Müller, Microoptics for efficient redirection of sunlight, Appl. Opt. 51 (2012) 2051-2056.

[11]. D. Appelfeld and S. Svendsen, Performance of a daylight-redirecting glassshading system, Energy and Buildings 64 (2013) 309-316.

[12]. I. Ullah and S. Shin, Concept of Solar Tower for Daylighting in Multi-floor Buildings, Journal of Green Science and Technology 1 (2013).

[13]. A. Rosemann, M. Mossman, and L. Whitehead, Development of a cost- effective solar illumination system to bring natural light into the building core, Solar Energy 82 (2008) 302-310.

[14]. I. Ullah and S. Shin, Development of Optical Fiber-based Daylighting System with Uniform Illumination, Journal of the Optical Society of Korea 16 (2012) 247-255.

[15]. I. Ullah and S. Shin, Uniformly Illuminated Efficient Daylighting System, Smart Grid and Renewable Energy 4 (2013) 161-166.

[16]. I. Ullah and S. Shin, Highly Concentrated Optical Fiber-Based Daylighting Systems for Multi-Floor Office Buildings, Energy and Buildings, 2014. http://dx.doi.org/10.1016/j.enbuild.2013.12.031 